\title{
AN EXPERIMENTAL INVESTIGATION INTO THE EFFECT OF THERMOSTAT SETTINGS ON THE ENERGY CONSUMPTION OF HOUSEHOLD REFRIGERATORS
}

\author{
Edy Susanto ${ }^{1,2}$, M. Idrus Alhamid ${ }^{2}$, Nasruddin $^{2}$, Budihardjo $^{2}$ \\ ${ }^{1}$ Faculty of Engineering, Universitas Samudra, Meurandeh, Langsa 24416, Indonesia \\ ${ }^{2}$ Department of Mechanical Engineering, Faculty of Engineering, Universitas Indonesia, Kampus UI \\ Depok, Depok 16424, Indonesia
}

(Received: December 2017 / Revised: December 2017 / Accepted: March 2018)

\begin{abstract}
Many household refrigerator owners do not control their thermostat settings. However, doing this could save energy consumption and also maintain the quality of stored food. This study presents the effect of regulated thermostat settings on household refrigerator energy consumption. The experiment was performed in a room chamber conditioned to temperature control at $25^{\circ} \mathrm{C}$. A household refrigerator was used as a test unit, with a cooling load placed inside the freezer component. The cooling load used was an M-package, in accordance with SNI IEC 15502: 2008. The test results reveal that household refrigerator energy consumption increases with higher thermostat settings. Increases in energy consumption range from $17.10 \%$ to $18.65 \%$, depending on the thermostat setting.
\end{abstract}

Keywords: Consumption energy; Refrigerator; Room chamber; Setting thermostat

\section{INTRODUCTION}

The household refrigerator is an integral part of our life. In Indonesia, the number of household refrigerators continues to rise as the population grows. Currently, household refrigerators rank second in household energy consumption after air conditioning, partly due to the fact that household refrigerators run continuously (Khan et al., 2013). The increasing number of household refrigerator users is due to improved household economies, easy availability of electricity and cheap prices (Hasanuzzaman et al., 2011). Meanwhile, a US survey in 2009 revealed that household refrigerators consume more than $25 \%$ of household electrical energy (EIA, 2015).

Many studies have analyzed the factors that influence increases in household refrigerator energy consumption. Factors studied include the increase in energy consumption caused by ambient temperature, door openings, thermostat settings and cooling loads (Saidur et al., 2002; Hasanuzzaman, 2008). These variables combine to constitute the dominant factors that affect increases in household refrigerator energy consumption. Liu et al. (2004) conducted an experimental study on two types of household refrigerators by varying the number of door openings and ambient temperature. Their study showed that if the temperature of the unit rises due to opening of the door, then energy consumption also increases by 10\% (Liu et al., 2004). Ozgun et al., performed optimization by varying the temperature and airflow into the evaporator to find household refrigerator energy efficiency (Sakalli et al., 2017).

\footnotetext{
*Corresponding author's email: mamak@eng.ui.ac.id, Tel: +62-21-5422-0808, Fax: +62-21-5422-0800 Permalink/DOI: https://doi.org/10.14716/ijtech.v9i2.1055
} 
In India, Bhatt conducted an experimental study of several brands of household refrigerators, each with a capacity of 165 liters. The tests were performed on two types of household refrigerator: single door and double door, using refrigerant HCFC 22. The thermostat settings varied with normal and maximum levels. The results showed that Specific Energy Consumption (SEC) varied between 3.23 and $4.19 \mathrm{kWh} / \mathrm{y} / \mathrm{L}$ for single door manual defrost refrigerators, and between 3.84 and $4.78 \mathrm{kWh} / \mathrm{y} / \mathrm{L}$ for double door auto defrost models (Bhatt, 2001). $\mathrm{kWh} / \mathrm{y} / \mathrm{L}$ is the unit of annual energy consumption to refrigerator volume, explaining the Specific Energy Consumption conditions (SEC).

As in the research conducted by Bhatt, the objective of this study is to experimentally analyze the impact of thermostat settings on increases of in household refrigerator energy consumption. Where the on-off compressor working time follows the temperature of the freezer set by the thermostat. As a refrigeration system component in the refrigerator that requires electrical energy.

\section{METHODOLOGY}

The special room used for testing is called the chamber room. The temperature and Relative Humidity $(\mathrm{RH})$ of this chamber room is controlled and the air flow rate in the room is not permitted to reach more than $0.25 \mathrm{~m} / \mathrm{s}$ (BSNI, 2008).

\subsection{Test Unit}

A two door household refrigerator type with a freezer space and fresh food compartment was used in the experiment. The specifications of the unit are shown in Table 1.

Table 1 Technical specifications of refrigerator-freezer test unit

\begin{tabular}{lc}
\hline \multicolumn{1}{c}{ Specifications } \\
\hline Freezer cabinet capacity (liters) & 95 \\
Fresh food cabinet capacity (liters) & 187 \\
Power rating (Watts) & 125 \\
Current rating (A) & 1.2 \\
Voltage (V) & 220 \\
Frequency (Hz) & 50 \\
Climate class & T \\
Refrigerant type & R600a \\
\hline
\end{tabular}

\subsection{Test Condition}

In the test, the environmental temperature was kept constant at $25 \pm 0.5^{\circ} \mathrm{C}$ and the relative humidity at $60 \pm 0.5 \%$. The most important variable was the thermostat settings, which were set at points 1, 3 and 4 out of the maximum value of 7 . The cooling load in the experiment used Mpackages placed in the main space and in the freezer door, as shown in Table 2.

\subsection{Instruments}

During the test, the door remained closed for the duration of the 48 hour test period. In order to measure the falling temperature in the cooling load (M-package) a T-type thermocouple is positioned in the center of the M-package.

The experiment was performed in a room chamber with at a temperature of $25 \pm 0.5^{\circ} \mathrm{C}$. A T-type thermocouple was used to measure the temperature around the test unit and a humidity transmitter with $\pm 10 \%$ accuracy was used to measure the relative humidity. Energy consumption was measured by using a digital YOKOGAWA WT-230 with an accuracy of $\pm 0.0015 \mathrm{~kW}$. A power meter was connected to a PC via RS-232 and LabView software used to save, analyze and display the data readings received on the PC monitor. A data logger was used 
to support direct measurements of temperature, relative humidity, DC voltage, AC voltage, DC current, AC current, frequency resistance and period.

Table 2 Load calculation

\begin{tabular}{lccc}
\hline \multicolumn{1}{c}{ Position } & $\begin{array}{c}\text { Package } \\
(\mathrm{kg})\end{array}$ & Quality (EA) & Weight $(\mathrm{kg})$ \\
\hline Top shelf & 1 & 4 & 4 \\
& 0.5 & 8 & 4 \\
& 0.125 & 1 & 0.125 \\
\hline Bottom shelf & 1 & 7 & 7 \\
& 0.5 & 5 & 2.5 \\
& 0.125 & 2 & 0.25 \\
\hline Door & 1 & 0 & 0 \\
& 0.5 & 6 & 3 \\
& 0.125 & 6 & 0.75 \\
\hline Total $(\mathrm{kg})$ & & & 21.63 \\
\hline
\end{tabular}

\subsection{Experimental Setup}

A household refrigerator with a freezer at the top and a fresh food compartment at the bottom was used for this study.

\subsubsection{Placement of humidity sensors and thermocouples}

Humidity sensors were placed inside the chamber room to measure the relative humidity around the refrigerator. Thermocouples were used to measure the temperature inside and outside the refrigerator. Several thermocouples were used, including three placed in the fresh food compartment. Each of the four thermocouples was inserted into the M-package in the freezer compartment and refrigerator door.

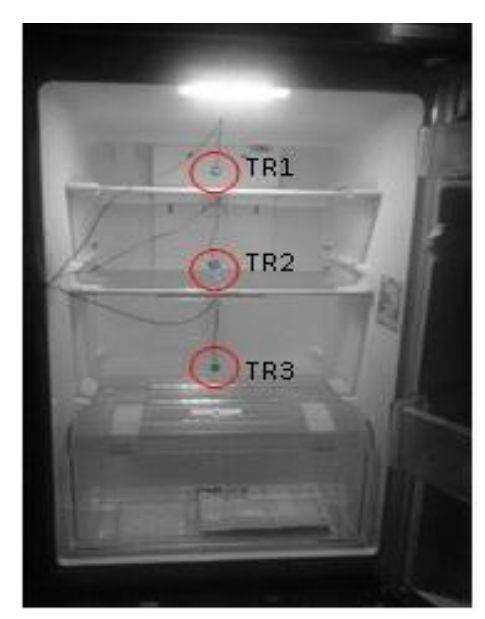

Figure 1 Placement of thermocouples in fresh food compartment (TR)

\subsubsection{Placement of load during test}

The cooling load used was an M-package, which has the same properties as lean meat. During the test process, the door remained closed. The M-package was inserted into the freezer and also the freezer door, as shown in Figures 2 and 3. 


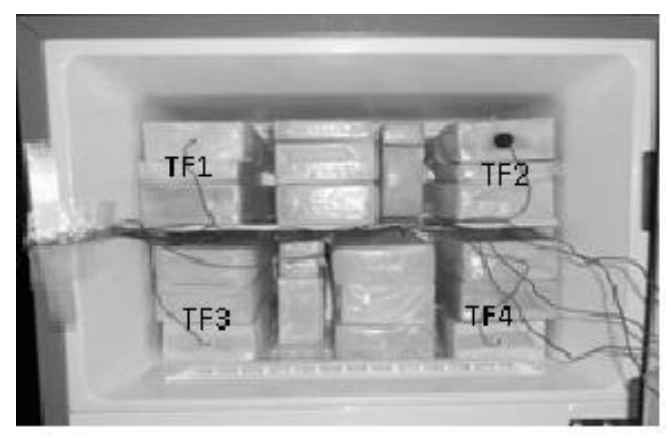

Figure 2 Position of thermocouples in M-package inside the freezer (TF)

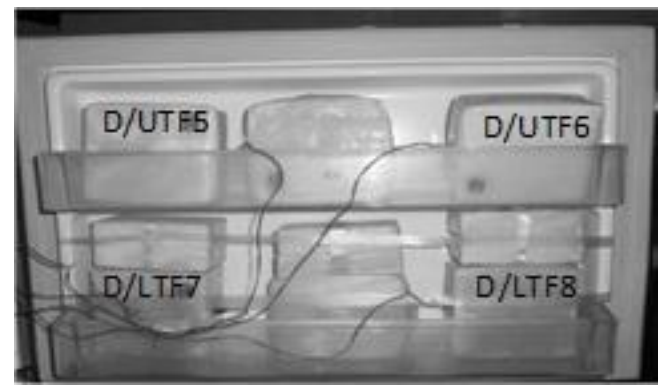

Figure 3 Position of thermocouples in M-package inside the freezer door (Door/Upper and Door/Lower)

\section{RESULTS AND DISCUSSION}

The length of time required for the test was 240 hours for one data. The study was conducted with different thermostat setting variations, at points 1,3 and 4; this only applied to the fresh food compartment. Meanwhile, the thermostat setting in the freezer was maintained at the maximum setting (7). The thermostat setting would determine the level of the temperature in the refrigerator, which would affect the increase in household refrigerator energy consumption. The humidity sensor only controlled the humidity in the test chamber, which should not exceed $75 \%$, according to test standards.

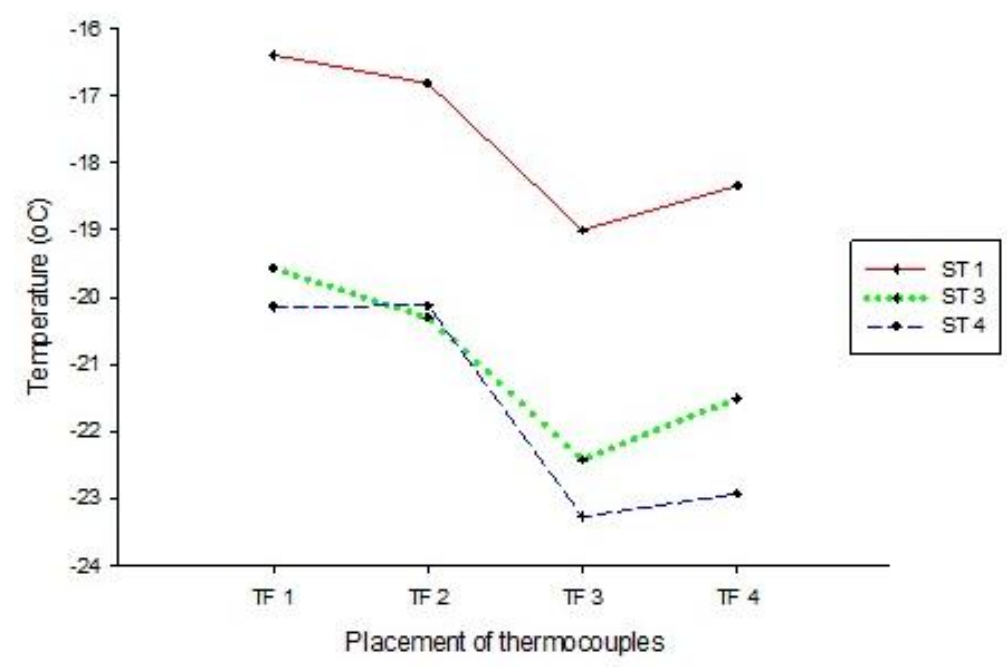

Figure 4 Temperatures in the freezer space

The thermostat is an automatic switch to break the current into the compressor engine or reconnect when the cooling temperature begins to decrease and the compressor engine begins to 
restart. From Figure 4, it can be seen that when the thermostat was changed from point 1 to point 3 , there was a very significant temperature drop, from $-16.39^{\circ} \mathrm{C}$ to $-19.57^{\circ} \mathrm{C}$. This was due to the work of the compressor continuously electric current, impact of the open switch contact when the cooling temperature had not been reached. However, the change in temperature from point 3 to point 4 did not change significantly, only by $0.55^{\circ} \mathrm{C}$. Similarly, the temperatures in the refrigerator door can be seen in Figure 5.

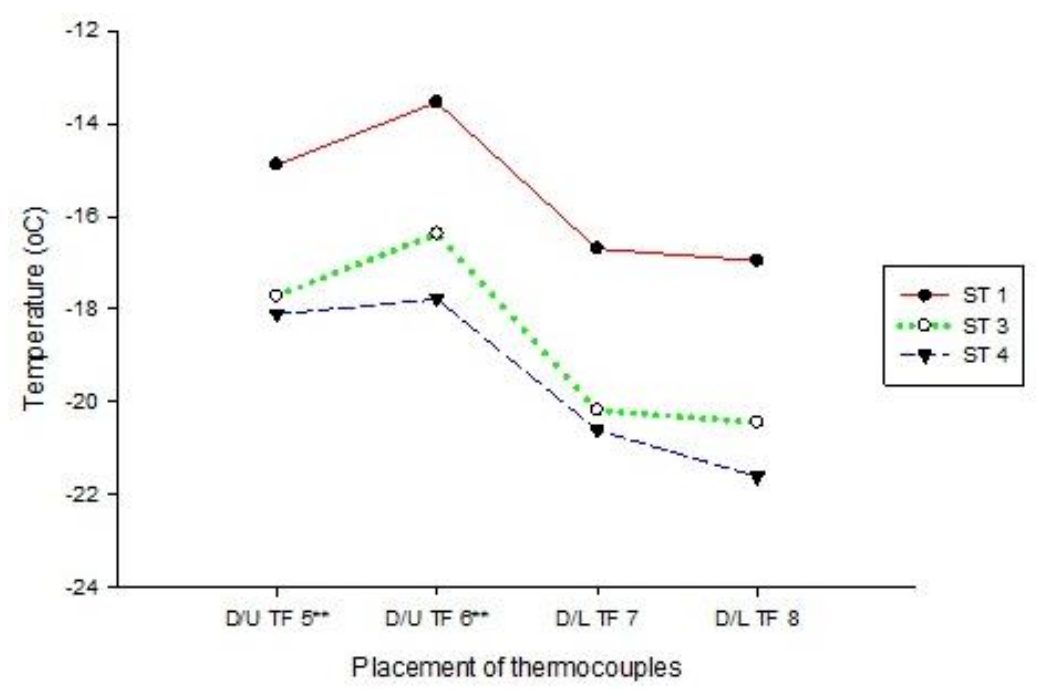

Figure 5 Temperatures in the freezer door

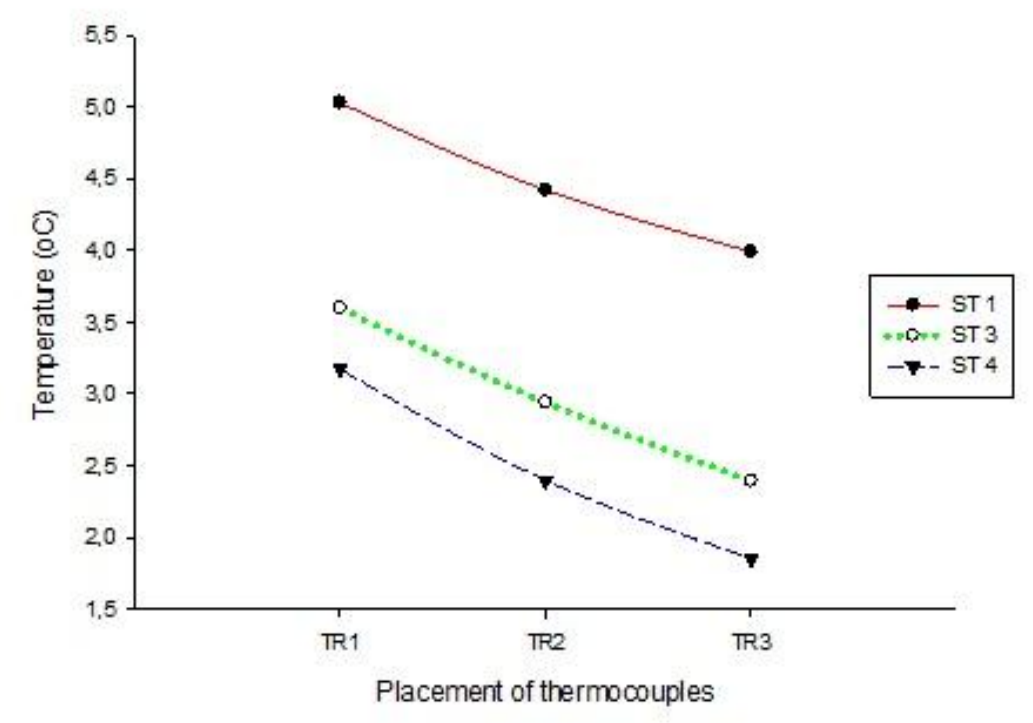

Figure 6 Fresh food compartment temperatures

The effect of the thermostat changes in the fresh food compartments shows a relatively similar trend. Each change in the thermostat caused a temperature drop of about $1{ }^{\circ} \mathrm{C}$; this can be seen in Figure 6. Increasing the value of the thermostat setting caused the temperature to fall, which increased the compressor work, so energy consumption also increased.

Figure 7 shows how raising the thermostat affected energy consumption. This increased significantly when the thermostat setting was increased from point 1 to point 3 . This increased energy consumption by $17.10 \%$, or $0.599 \mathrm{kWh} /$ day, and by $18.65 \%$ when the thermostat was turned up to point 4 , or by $0.608 \mathrm{kWh} /$ day. The resulting trend is the same as that of Masjuki 
and Grimes (Grimes et al., 1977; Masjuki et al., 2001). The Masjuki test results show a temperature decrease from $-4^{\circ} \mathrm{C}$ (position setting 1) to $-13.3^{\circ} \mathrm{C}$ (position setting 4 ).

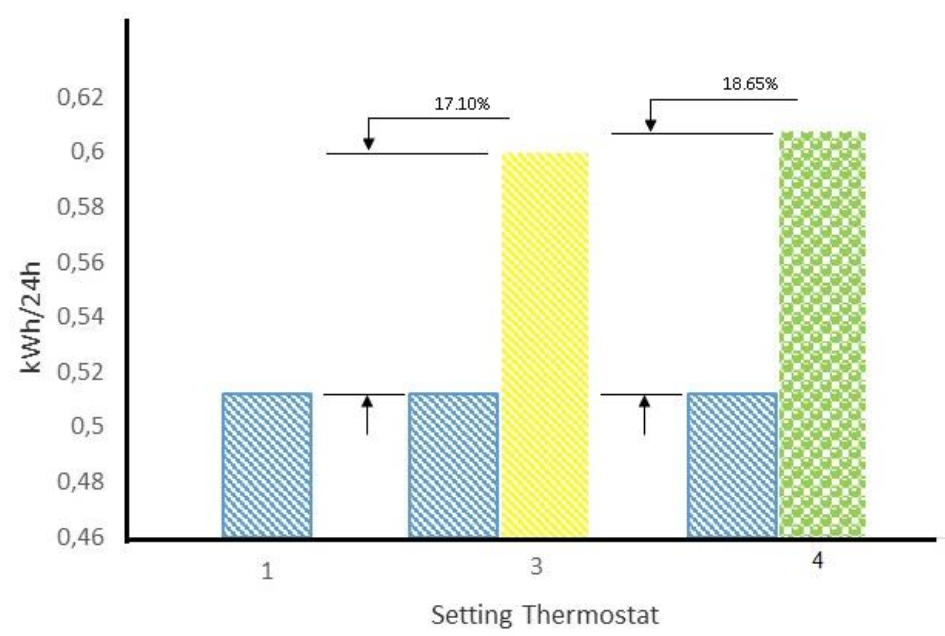

Figure 7 Effect of energy consumption on regulated increases

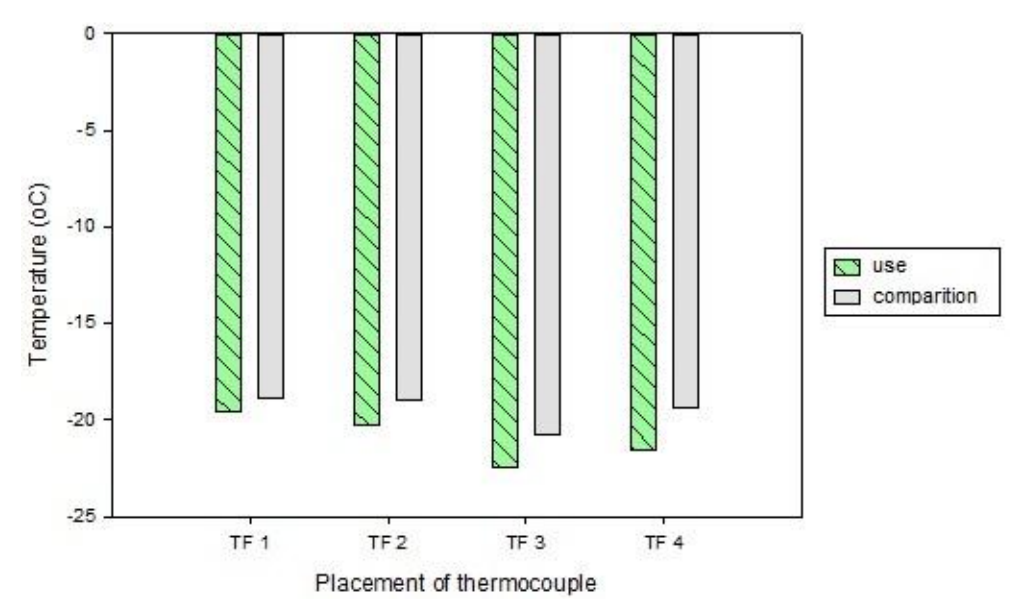

Figure 8 Temperature comparison in the freezer

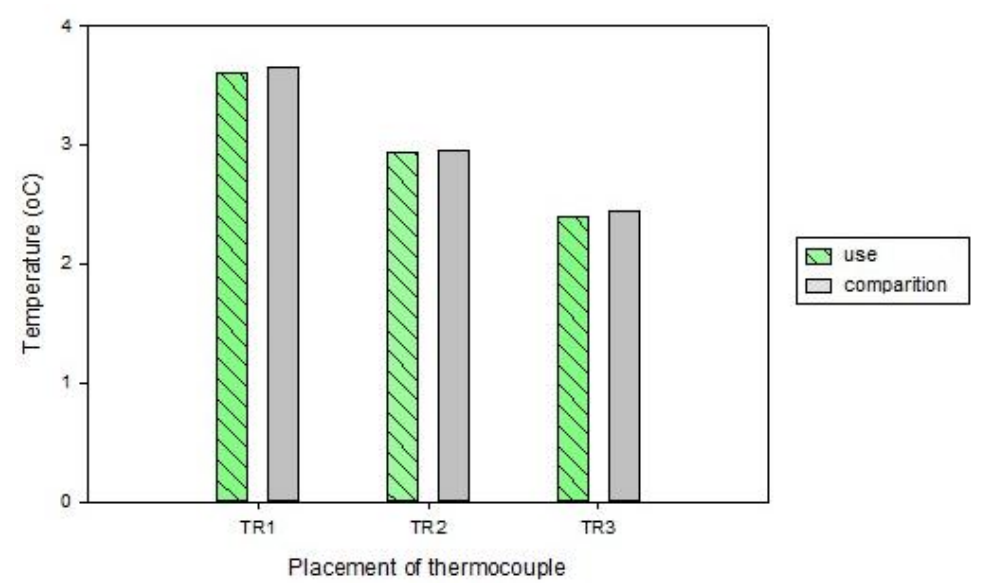

Figure 9 Temperature comparison in the fresh food compartment

This study also compares the test results on the condition of the same refrigerator both volume and brand and mass M-package. The results can be seen in Figures 8 and 9, which show the 
differences, despite the fact that they have relatively similar tendencies. Many factors that lead to the measurement results are different, partly due to the preparation of unequal $\mathrm{M}$ packets. This had an impact on airflow blocks in different refrigerators, which caused uniform temperature conditions to become uneven. Temperature uniformity affects compressor work, as a component of energy consumption, so the difference in energy consumption is greater than $0.1 \mathrm{kWh} /$ day.

\section{CONCLUSION}

Based on the experiment, an increase in energy consumption of $0.175 \mathrm{kWh} /$ day was obtained when the thermostat setting was increased from point 1 to point 3 . There was also a slight increase in energy consumption of $0.016 \mathrm{kWh} /$ day when this setting was increased from point 3 to point 4 . With the thermostat setting change from point 3 to point 4 , there was no significant change in energy consumption or drop in temperature, so it can be concluded that setting the thermostat to point 3 is sufficient to keep food fresh. While even testing the energy consumption of the same refrigerator is not necessarily the same result.

\section{ACKNOWLEDGMENT}

The authors would like to thank the Directorate of Research and Community Service of the University of Indonesia through the "University of Indonesia Infrastructure Development Grants", under contract number 0219A/SK/R/UI/2012.

\section{REFERENCES}

Bhatt, M.S., 2001. Domestic Refrigerators: Field Studies and Energy Efficiency Improvement. Journal of Scientitic \& Industrial Research, Volume 60(7), pp. 591-600

EIA, 2015. Drivers of U.S. Household Energy Consumption, 1980-2009 Washington: U.S. Departemen of Energy

Grimes, J.W., Mulroy, W., Shomaker, B.L., 1977. Effect of Usage Conditions on Household Refrigerator-freezer and Freezer Energy Consumption. ASHRAE Transactions, Volume 83(1), pp. 818-828

Hasanuzzaman, M., Saidur, R., Masjuki, H., 2011. Effects of Different Variables on Moisture Transfer of Household Refrigerator-freezer. Energy Education Science and Technology. Part A. Energy Science and Research, Volume 27(2), pp. 401-418

Hasanuzzaman, Md., Saidur, R., Masjuki, H.H., 2008. Investigation of Energy Consumption and Energy Saving of Refrigerator-freezer during Open and Closed Door Condition. Journal of Applied Sciences, Volume 8(10), pp. 1822-1831

Indonesia National Standard Organisation (BSNI), 2008. Refrigerator for Household Characteristics and Test Method

Khan, Md.I.H., Afroz, H.M., Rohoman, M.A., Faruk, M., Salim, M., 2013. Effect of Different Operating Variables on Energy Consumption of Household Refrigerator. International Journal of Energy Engineering, Volume 3(4), pp. 144-150

Liu, D.-Y., Chang, W.-R., Lin, J.-Y. 2004. Performance Comparison with Effect of Door Opening on Variable and Fixed Frequency Refrigerators/freezers. Applied Thermal Engineering, Volume 24(14-15), pp. 2281-2292

Masjuki, H., Saidur, R., Choudhury, I., Mahlia, T., Ghani, A., Maleque, M., 2001. The Applicability of ISO Household Refrigerator-freezer Energy Test Specifications in Malaysia. Energy, Volume 26(7), pp. 723-737

Saidur, R., Masjuki, H., Choudhury, I., 2002. Role of Ambient Temperature, Door Opening, Thermostat Setting Position and Their Combined Effect on Refrigerator-freezer Energy Consumption. Energy Conversion and Management, Volume 43(6), pp. 845-854 
Sakalli, Ö., Kerpiççi, H., Kuddusi, L., 2017. A Study on Optimizing the Energy Consumption of a Cold Storage Cabinet. Applied Thermal Engineering, Volume 112, pp. 424-430 